\title{
ARAHAN KETERPADUAN PEMANFAATAN DAN PENGENDALIAN PEMBANGUNAN PERUMAHAN DAN KAWASAN PERMUKIMAN PADA LINTAS DAERAH KABUPATEN/KOTA
}

\section{INTEGRATED DIRECTIONS OF THE UTILIZATION AND CONTROL OF RESIDENTIAL AND RESIDENTIAL AREA IN CROSS OF REGENCY/CITY}

\author{
Mohtana Kharisma Kadri*, Faisal** \\ * Institut Teknologi Kalimantan \\ Jl. Soekarno Hatta No.KM 15, Karang Joang, Kec. Balikpapan Utara, Kota Balikpapan, Kalimantan Timur \\ 76127 \\ Email: mohtana.kharisma@lecturer.itk.ac.id \\ ** IAP Kaltim \\ Jl. Keledang No.48, Gn. Kelua, Kec. Samarinda Ulu, Kota Samarinda, Kalimantan Timur 75243
}

Diterima: 8 Desember 2020; Direvisi: 22 Desember 2020; Disetujui: 28 Desember 2020

\begin{abstract}
ABSTRAK
Aglomerasi suatu kawasan sering kali disebabkan adanya konurbasi suatu wilayah dengan dipengaruhi adanya perkembangan kawasan perumahan dan permukiman dalam suatu wilayah sehingga perlu adanya arahan terkait pemanfaatan lahan dan pengendalian pembangunan perumahan dan kawasan permukiman khususnya yang berada pada kawasan lintas daerah kabupaten/kota yang ada di Provinsi Kalimantan Timur. Adapun tujuannya dari penelitian ini adalah agar tidak terjadi perbedaan konsep pengembangan ruang perkotaan dan permukiman pada daerah lintas kabupaten/kota tersebut, dan keterpaduan rencana pemanfaatan dan pengendalian yang lebih detail dapat terwujud yakni perumahan dan kawasan permukiman yang berkualitas dan berkelanjutan. Adapun metode yang digunakan adalah metode diskriptif kualitatif dan kuantitatif, dengan bersumber dari data-data sekunder dan data primer. Adapun arahan keterpaduan pemanfaatan dan pengendalian pembangunan perumahan dan kawasan permukiman pada lintas daerah kabupaten/kota diatur dalam sebuah peraturan zonasi yang terbagi atas dua peruntukan yaitu kawasan peruntukan permukiman perkotaan dan kawasan peruntukan permukiman perdesaan. Pada masing-masing peraturan tersebut mengatur terkait perijinan pengembangan perumahan, intensitas bangunan, Sarana dan prasarana pendukung dan moda sarana angkutan masal, pengembangan Fasilitas Lainnya dan Larangan pengembangan lahan.
\end{abstract}

Kata kunci: Aglomerasi, Konurbasi, Perumahan permukiman lintas daerah.

\begin{abstract}
Agglomeration of an area is often caused by the conurbation of an area which is influenced by the development of housing and settlement areas in an area so that there is a need for directions related to land use and control of housing development and settlement areas, especially those in crossdistrict / municipal areas in Kalimantan Province. East. The purpose of this research is that there is no difference in the concept of urban spatial development and settlements in the cross-regency / municipal area, and that more detailed utilization and control plans can be realized, namely quality and sustainable housing and settlement areas. The method used is descriptive qualitative and quantitative methods, sourced from secondary data and primary data. The directions for the integrated use and control of housing development and settlement areas across regencies / municipalities are regulated in a zoning regulation which is divided into two designations, namely areas designated for urban settlements and areas designated for rural settlements. Each of these
\end{abstract}


Arahan Keterpaduan Pemanfaatan dan Pengendalian Pembangunan Perumahan dan Kawasan Permukiman Pada Lintas Daerah Kabupaten/Kota

Mohtana Kharisma Kadri, Faisal

regulations regulates housing development licensing, building intensity, supporting facilities and infrastructure and mass transportation modes, development of other facilities and prohibition of land development.

Keywords: Agglomeration, Conurbation and Housing Inter-regional settlements.

\section{PENDAHULUAN}

Pembangunan perumahan dan kawasan permukiman merupakan kebutuhan dasar manusia yang mempunyai fungsi strategis sebagai pusat pendidikan keluarga, persemaian budaya, dan peningkatan kualitas generasi yang akan datang, serta merupakan pengejawantahan jati diri. Salah satu perwujudan tercapainya kesejahteraan rakyat ditandai dengan meningkatnya kualitas kehidupan yang layak dan bermartabat melalui pemenuhan kebutuhan papan sebagai salah satu kebutuhan dasar manusia. Demikian pembangunan perumahan dan kawasan permukiman merupakan salah satu bidang strategis dalam upaya pembangunan manusia Indonesia yang seutuhnya dan pembangunan perumahan dan kawasan permukiman merupakan kegiatan yang bersifat multi sektor, yang hasilnya langsung menyentuh salah satu kebutuhan dasar masyarakat. Berdasarkan Undang-Undang No 23 Tahun 2014 tentang Pemerintahan Daerah, pembangunan perumahan dan kawasan permukiman menjadi salah satu urusan wajib yang berkaitan dengan pelayanan dasar, sehingga harus dilaksanakan oleh pemerintah kota/kabupaten. Namun demikian, masalah pembangunan perumahan dan kawasan permukiman merupakan tanggung jawab bersama antara pemerintah, pemerintah provinsi, pemerintah kabupaten/kota, dunia usaha dan masyarakat sesuai peran masing- masing.

Pemenuhan kebutuhan rumah layak huni dan lingkungan sehat tentunya menjadi kewajiban masyarakat sendiri, pemerintah dalam hal ini mempunyai tugas untuk menciptakan iklim pembangunan yang kondusif sehingga memberikan peluang kepada dunia usaha menyediaan perumahan dan kawasan permukiman.

Persoalan yang dihadapi dalam pemenuhan perumahan dan kawasan permukiman yaitu tingginya laju pertumbuhan penduduk yang tidak mampu diimbangi dengan pembangunan perumahan dan permukiman yang disebabkan karena semakin sulitnya lahan untukpembangunan perumahan dan permukiman, sehingga semakin meningkatkan selisih backlog (Kesenjangan antara jumlah rumah yang terbangun dengan jumlah rumah yang dibutuhkan).

Permasalahan backlog merupakan permasalahan yang dihadapi oleh berbagai provinsi di Indonesia termasuk Provinsi Kalimantan Timur. Provinsi Kalimantan Timur berada pada urutan 21 dari 33 Provinsi yang terdapat backlog (e-rtlh, 2019). Tingginya angka backlog di Provinsi Kalimantan Timur diakibatkan oleh tingkat pendapatan masyarakat untuk bisa memiliki rumah layak huni sehingga masyarakat dalam memenuhi kebutuhan akan rumah melakukan hal - hal yang ilegal dan bermukim dikawasan hinterland atau perbatasan sehingga menjadi salah satu penyebab timbulnya kawasan kumuh dan permukiman yang tidak sesuai dengan tata ruang di berbagai daerah Kabupaten dan Kota di Provinsi Kalimanatan Timur (Pedoman Identifikasi Kawasan Permukiman Kumuh Daerah Penyangga Kota Metropolitan)

Dinamika perkembangan pemanfaatan ruang di wilayah Provinsi Kalimantan Timur, khususnya di setiap Kabupaten/Kota Di Provinsi Kalimantan Timur permukiman tersebar akibat adanya aktivitas ekonomi disekitar mereka dan pola hidup masyarakat (Budaya) sehingga warga cenderung bermukim di lokasi yang dekat dengan lokasi tambang dan bantaran sungai dan laut, serta pada kawasan lintas wilayah.

Hal ini ditambah dengan fenomena yang terjadi terkait dengan adanya isu pemindahan Ibu Kota Negara di Provinsi Kalimantan Timur mengakibatkan banyaknya investor maupun perseorangan yang mencari lahan disekitar kawasan kota balikpapan, kota samarinda dan kabupaten penajam (Antarnews.com,2019). Jika hal ini terjadi maka akan menyebabkan hampir sebagain kawasan yang berada didaerah perbatasan wilayah kota maupun kabupaten (lintas 
wilayah) lahannya sudah dikuasai oleh investor/developer dan perseorangan, kemungkinan terjadinya konurbasi dibeberapa daerah akan terjadi lagi.

Jika hal tersebut tetap dibiarkan maka kemungkinan akan terjadi proses Aglomerasi seperti yang terjadi pada lokasi ibu kota negara sebelumnya, jika tidak ada konsep penanganan atau pencegahan pada kawasan lintas wilayah tersebut maka proses yang pertama kali muncul adalah konurbasi kawasan permukiman pada kawasan lintas wilayah/perbatasan.

Oleh sebab itu penelitian ini dilakukan untuk mendapatkan arahan keterpaduan pemanfaatan dan pengendalian pembangunan perumahan dan kawasan permukiman pada lintas daerah kabupaten/kota (lintas wilayah) di provinsi Kalimantan timur.

\section{METODE}

Metodologi Pelaksanaan dilakukan agar langkah-langkah kegiatan yang disusun berurutan oleh tim penyusun, untuk memudahkan pelaksanaan pekerjaan dan pengawasan, sehingga dapat mencapai hasil yang baik dan tepat waktu. Langkah-langkah kegiatan yang akan dilaksanakan secara garis besar disajikan dalam penjabaran berikut ini.

1. Tahap persiapan yang dilakukan adalah pembentukan tim, koordinasi eksternal dan internal tim, membuat kerangka pelaksanaan kegiatan dan jadwal pelaksaan pekerjaan, studi pustaka dan persiapan survei

2. Pengumpulan data, dengan menggunakan dua teknik yaitu survei lapangan dengan observasi lapangan dan wawancara dengan pemangku kepentingan. Kemudian menggunakan survei sekunder terkiat data-data instansi yang diperlukan.

3. Kompilasi data dan analisis analisis arah pengembangan perumahan dan kawasan permukiman di daerah kabupaten/kota yang berbatasan terhadap rencana pengembangan wilayah kabupaten/kota secara keseluruhan; berikut data-data yang diperlukan

a. Data Kependudukan tiap kecamatan

b. Data kondisi perumahan dan permukiman di daerah kabupaten/kota yang berbatasan

c. Data tentang prasarana, sarana, dan utilitas umum lintas daerah kabupaten/kota yang berbatasan;

d. Data perizinan pembangunan perumahan dan kawasanpermukiman yang telah diterbitkan;

e. peta dalam dokumen RTRW meliputi:

- peta batas administrasi;

- peta penggunaan lahan eksisting;

- peta informasi kebencanaan dan rawan bencana;

- peta kondisi tanah antara lain peta geologi, hidrologi, Topografi

- peta-peta identifikasi potensi sumberdaya alam; dan

- peta rencana struktur dan pola ruang;

f. peta daerah kabupaten/kota yang berbatasan dengan skala sekurang-kurangnya 1 : 25.000 sampai dengan $1: 50.000$;

g. citra satelit untuk memperbaharui (update) peta dasar dan membuat peta tutupan lahan; dan

h. peta status perizinan lokasi pemanfaatan tanah.

4. Pada penelitian ini, metodologi yang digunakan adalah analisis kuantitatif untuk mendapatkan gambaran masa depan pada kawasan perbatasan di kalimantan timur dan melakukan kajian analisis dengan menggunakan metode deskriptif kualitatif untuk mendapat arahan yang ada pada kawasan tersebut. Pengambilan sampel menggunakan random sampling berada di beberapa lokasi setiap perbatasan antar wilayah yang ada di kalimantan timur. Proses analisis dilakukan dengan menilai kondisi kawasan perencanaan saat ini dengan mengacu pada metode pendekatan kajian serta standar dan 
peraturan yang digunakan. Dalam kegiatan analisa harus diketahui pula dengan jelas kondisi potensi dan masalah yang ada di lokasi sehingga dapat dibuat suatu arahan penanganan kawasan secara lebih baik dan sesuai dengan kebutuhannya;

\section{HASIL DAN PEMBAHASAN}

RTRWP Kalimantan Timur menjadi pedoman penataan ruang wilayah termasuk pemanfaatan ruang dan pembangunan prasarana dan pengadaan sarana yang bersifat lintas kabupaten dan atau kota di wilayah Provinsi Kalimantan Timur. Penataan ruang wilayah internal kabupaten dan atau kota RTRWP Kalimantan Timur menjadi arahan agar terwujud penataan ruang kabupaten dan kota yang sinergis, simbiosis mutualistis, berdaya guna, berhasil guna, bermanfaat bagi masyarakat dalam kondisi alam yang asri dan lestari.

Dalam Perda Provinsi Kalimantan Timur nomor 1 tahun 2016 Pasal 29 ayat (1) huruf $\mathrm{f}$ bab IV menyebutkan bahwa Rencana Kawasan Budidaya Provinsi Kalimantan Timur terbagi menjadi delapan peruntukan fungsi kawasan dan salah satu diantaranya yaitu kawasan Permukiman, kawasan permukiman dengan luas 396.266 Ha, yang dimaksudkan pada pada pasal ini merupakan kawasan yang potensial dikembangkan sebagai kawasan permukiman yang meliputi permukiman perkotaan dan permukiman perdesaan.

Pola pergerakan penduduk Provinsi Kalimantan Timur juga dapat diidentifikasi dengan melihat sejauh mana interaksi penduduk antara suatu daerah dengan daerah lainnya. Dalam mengetahui pola interaksi seberapa besar interaksi masyarakat Kalimantan Timur digunakan analisis model Gravitasi Hansen yang menghitung antara penduduk dari ibu Kota Provinsi dengan penduduk di Ibukota daerah dan kota, dengan menggunakan analisis interaksi ini, dapat diprediksi lokasi dari permukiman penduduk berdasarkan daya tarik masing - masing lokasi, adapun hasil dari analisis interaksi provinsi Kalimantan Timur dapat dilihat pada tabel 1.

Tabel 1. Analisis Interaksi Ibukota Provinsi dengan Ibukota Kabupaten Kota

\begin{tabular}{|c|c|c|c|c|c|c|c|}
\hline No & $\begin{array}{c}\text { Kabupaten/ } \\
\text { kota }(\mathrm{a})\end{array}$ & $\begin{array}{c}\text { Ibukota } \\
\text { Provinsi (b) }\end{array}$ & $\begin{array}{c}\text { Jumlah } \\
\text { Penduduk (a) }\end{array}$ & $\begin{array}{c}\text { Jumlah } \\
\text { Penduduk (b) }\end{array}$ & $\begin{array}{c}\operatorname{Jarak}(\mathrm{a}) \\
\text { ke (b) }\end{array}$ & Nilai & $\begin{array}{c}\text { Kriteria } \\
\text { Interaksi }\end{array}$ \\
\hline 1 & Paser & Samarinda & 274.206 & 843.446 & 260 & 2.189 & Rendah \\
\hline 2 & Kutai Barat & Samarinda & 146.998 & 843.446 & 334 & 2.085 & Rendah \\
\hline 3 & $\begin{array}{l}\text { Kutai } \\
\text { Kartanegara }\end{array}$ & Samarinda & 752.091 & 843.446 & 31 & 2.947 & sedang \\
\hline 4 & Kutai Timur & Samarinda & 347.468 & 843.446 & 176 & 2.818 & Rendah \\
\hline 5 & Berau & Samarinda & 220.601 & 843.446 & 547 & 1.139 & Rendah \\
\hline 6 & $\begin{array}{l}\text { Penajam } \\
\text { Paser Utara }\end{array}$ & Samarinda & 157.711 & 843.446 & 130 & 5.275 & Tinggi \\
\hline 7 & Balikpapan & Samarinda & 636.012 & 843.446 & 112 & 1.852 & Rendah \\
\hline 8 & Bontang & Samarinda & 170.611 & 843.446 & 108 & 6.230 & Tinggi \\
\hline 9 & $\begin{array}{l}\text { Mahakam } \\
\text { Ulu }\end{array}$ & Samarinda & 26.305 & 843.446 & 600 & 1.362 & Rendah \\
\hline
\end{tabular}

Sumber : Hasil Analisis (2019)

Analisis sebaran kepadatan penduduk untuk 20 tahun kedepan menunjukkan persebaran penduduk pada luasan Kabupaten/Kota yang diproyeksikan berdasarkan data runtun waktu (bisa dilihat pada tabel 2). Melalui analisi metode analisis bunga berganda diketahui jumlah penduduk Provinsi Kalimantan Timur 20 tahun mendatang, yakni di tahun 2019 berjumlah 3.703.893 jiwa, kemudian 10 tahun berikutnya di tahun 2028 berjumlah 4.350 .545 jiwa. Kemudian pada 20 tahun berikutnya di tahun 2038 berjumlah 5.224.108 jiwa, hal ini menunjukkan pertumbuhan jumlah penduduk di Provinsi Kalimantan Timur terus meningkat dan akan berimpilkasi dengan peningkatan jumlah kebutuhan rumah pada masyarakat Provinsi Kalimantan Timur. 
Tabel 2. Proyeksi penduduk 20 tahun kedepan

\begin{tabular}{|c|c|c|c|c|c|c|}
\hline \multirow{2}{*}{ No } & \multirow{2}{*}{ Kabupaten/kota } & \multicolumn{5}{|c|}{ Pertumbuhan penduduk ( jiwa ) } \\
\hline & & 2019 & 2023 & 2028 & 2033 & 2038 \\
\hline 1 & Paser & 284.537 & 306.380 & 336.057 & 368.608 & 404.313 \\
\hline 2 & Kutai Barat & 148.207 & 150.656 & 153.773 & 156.955 & 160.202 \\
\hline 3 & Kutai Kartanegara & 781.586 & 844.093 & 929.301 & 1.023 .111 & 1.126 .391 \\
\hline 4 & Kutai Timur & 371.376 & 424.241 & 501.028 & 591.712 & 698.809 \\
\hline 5 & Berau & 230.633 & 252.088 & 281.733 & 314.865 & 351.894 \\
\hline 6 & Penajam Paser Utara & 160.817 & 167.215 & 175.571 & 184.345 & 193.557 \\
\hline 7 & Balikpapan & 653.496 & 689.918 & 738.314 & 790.104 & 845.528 \\
\hline 8 & Samarinda & 869.794 & 924.985 & 998.925 & 1.078 .774 & 1.165 .007 \\
\hline 9 & Bontang & 176.886 & 190.137 & 208.106 & 227.772 & 249.297 \\
\hline 10 & Mahakam Ulu & 26.560 & 27.078 & 27.739 & 28.416 & 29.110 \\
\hline \multicolumn{2}{|c|}{ Jumlah } & 3.703 .893 & 3.976 .790 & 4.350 .545 & 4.764 .663 & 5.224 .108 \\
\hline
\end{tabular}

Sumber : Hasil Analaisis (2019)

Analisis proyeksi penduduk berdasarkan kepadatan penduduk berfungsi untuk menunjukkan sejauh mana kepadatan penduduk provinsi Kalimantan Timur untuk 20 tahun mendatang, hasil analisis kepadatan jumlah penduduk dapat dilihat pada diagram 1 .

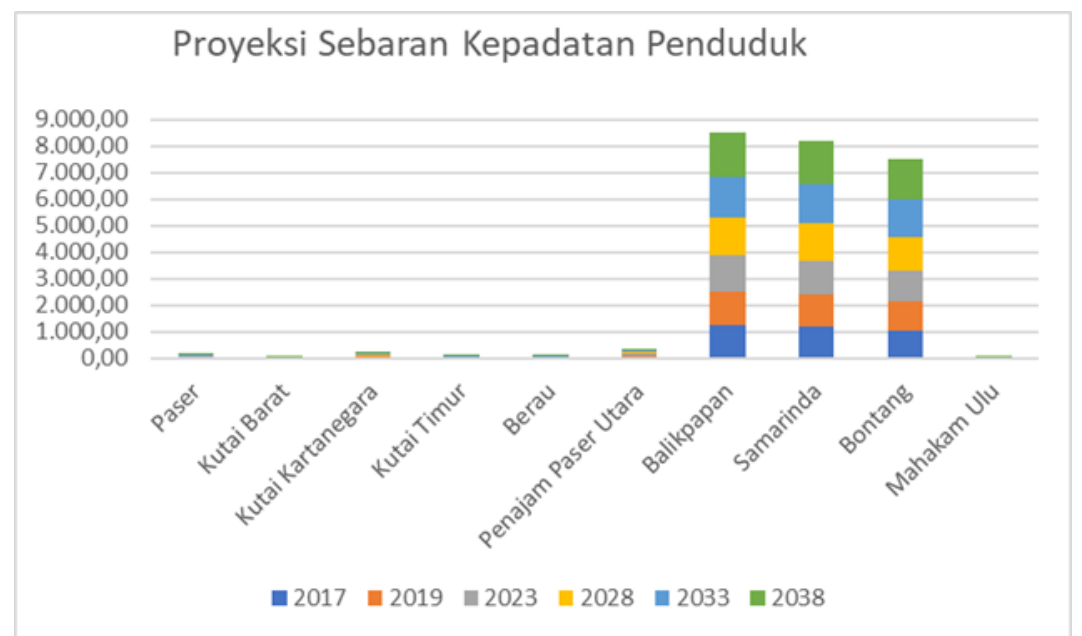

Diagram 1. Proyeksi sebaran kepadatan penduduk berdasarkan kota/kabupaten Sumber : Hasil Analisis (2019)

Berdasarkan analisis proyeksi kepadatan penduduk Provinsi Kalimantan Timur maka dapat diketahui kepadatan penduduk yang terbesar pada tahun 2038 berada pada Kota Balikpapan, sehingga kebutuhan akan lahan kawasan permukiman kedepannya akan semakin sulit di wilayah administrasi Kota Balikpapan.

Data status rumah dan kondisi rumah yang ada di Provinsi Kalimantan timur dapat dilihat pada tabel 3.

Tabel 3. Jumlah rumah di Provinsi Kalimantan Timur

\begin{tabular}{|c|c|c|c|c|c|c|c|c|c|}
\hline \multirow[b]{2}{*}{ No } & \multicolumn{9}{|c|}{ Status Kepemilikan Tempat Tinggal (Unit) } \\
\hline & $\begin{array}{c}\text { Kabupaten } \\
\text { /Kota }\end{array}$ & $\begin{array}{c}\text { Milik } \\
\text { Sendiri }\end{array}$ & Kontrak & Sewa & $\begin{array}{l}\text { Bebas } \\
\text { sewa }\end{array}$ & $\begin{array}{l}\text { Rumah } \\
\text { Dinas }\end{array}$ & $\begin{array}{c}\text { Rumah } \\
\text { Orang } \\
\text { Tua }\end{array}$ & Lainnya & Total \\
\hline 1 & Samarinda & 122761 & 10915 & 48984 & 5782 & 2820 & 14428 & - & 496656 \\
\hline
\end{tabular}


Arahan Keterpaduan Pemanfaatan dan Pengendalian Pembangunan Perumahan dan Kawasan Permukiman Pada Lintas Daerah Kabupaten/Kota

Mohtana Kharisma Kadri, Faisal

\begin{tabular}{|c|c|c|c|c|c|c|c|c|c|}
\hline \multirow[b]{2}{*}{ No } & \multicolumn{9}{|c|}{ Status Kepemilikan Tempat Tinggal (Unit) } \\
\hline & $\begin{array}{l}\text { Kabupaten } \\
\text { /Kota }\end{array}$ & $\begin{array}{l}\text { Milik } \\
\text { Sendiri }\end{array}$ & Kontrak & Sewa & $\begin{array}{l}\text { Bebas } \\
\text { sewa }\end{array}$ & $\begin{array}{l}\text { Rumah } \\
\text { Dinas }\end{array}$ & $\begin{array}{c}\text { Rumah } \\
\text { Orang } \\
\text { Tua }\end{array}$ & Lainnya & Total \\
\hline 2 & $\begin{array}{l}\text { Kutai } \\
\text { Kartanegara }\end{array}$ & 136739 & 1669 & 9676 & 1966 & 9401 & 16330 & 168 & 407821 \\
\hline 3 & Bontang & 28547 & 1462 & 12722 & 1302 & 3352 & 3512 & - & 101793 \\
\hline 4 & Kutai Timur & 59404 & 2421 & 9902 & 7452 & 581 & 3761 & - & 210630 \\
\hline 5 & Berau & 49635 & 3491 & 5037 & 3324 & 1507 & 2161 & 1412 & 159761 \\
\hline 6 & Balikpapan & 112086 & 24335 & - & 19324 & 6147 & - & - & 419197 \\
\hline 7 & $\begin{array}{l}\text { Penajam } \\
\text { Paser Utara }\end{array}$ & 60892 & 194 & 3573 & 2400 & 7229 & 3317 & - & 155211 \\
\hline 8 & Paser & 52997 & 1063 & 4130 & 1866 & 3467 & 3975 & - & 140238 \\
\hline 9 & Kutai Barat & 28488 & 427 & 4023 & 1947 & 2524 & 5511 & 102 & 64570 \\
\hline 10 & $\begin{array}{l}\text { Mahakam } \\
\text { Ulu }\end{array}$ & 5137 & 25 & 17 & 20 & 50 & 150 & 12 & 5411 \\
\hline & Total & 656626 & 46002 & 98064 & 45383 & 37078 & 53145 & 1694 & 2158288 \\
\hline
\end{tabular}

Sumber : Hasil Analisis

Tabel 4. Kondisi rumah di Provinsi Kalimantan Timur

\begin{tabular}{|c|c|c|c|c|c|c|}
\hline \multirow[b]{2}{*}{ No } & \multirow[b]{2}{*}{$\begin{array}{c}\text { Kabupaten } \\
\text { /Kota }\end{array}$} & \multicolumn{4}{|c|}{ Status Kepemilikan Tempat Tinggal (Unit) } & \multirow[b]{2}{*}{ Total } \\
\hline & & $\begin{array}{c}\text { Tidak Layak } \\
\text { Huni }\end{array}$ & $\begin{array}{c}\text { Rumah } \\
\text { Panggung }\end{array}$ & $\begin{array}{l}\text { Rumah } \\
\text { Terapung }\end{array}$ & $\begin{array}{c}\text { Rusun/ } \\
\text { apartemen }\end{array}$ & \\
\hline 1 & Samarinda & 174065 & 22377 & - & 6 & 196448 \\
\hline 2 & $\begin{array}{l}\text { Kutai } \\
\text { Kartanegara }\end{array}$ & 140125 & - & 35824 & - & 175949 \\
\hline 3 & Bontang & 50896 & 0 & 0 & 1 & 50896 \\
\hline 4 & Kutai Timur & 83520 & - & - & - & 83520 \\
\hline 5 & Berau & 58013 & 8500 & 54 & - & 66567 \\
\hline 6 & Balikpapan & 160227 & 3242 & - & 764 & 164233 \\
\hline 7 & $\begin{array}{l}\text { Penajam } \\
\text { Paser Utara }\end{array}$ & 40014 & 87 & - & - & 40101 \\
\hline 8 & Paser & 67439 & 0 & 0 & 0 & 40101 \\
\hline 9 & Kutai Barat & 28488 & 0 & 0 & 0 & 28488 \\
\hline 10 & $\begin{array}{l}\text { Mahakam } \\
\text { Ulu }\end{array}$ & 203 & 3664 & 1544 & 0 & 5411 \\
\hline & Total & 802990 & 37870 & 37422 & 771 & 879052 \\
\hline
\end{tabular}

Sumber : Hasil Analisis

Tabel 5. Rincian Rencana Pengembangan Kawasan Peruntukan Permukiman di Provinsi Kalimantan Timur

\begin{tabular}{|c|c|c|c|c|}
\hline No & Kabupaten /Kota & $\begin{array}{c}\text { Luasan Eksisting } \\
(\mathrm{Ha})\end{array}$ & $\begin{array}{c}\text { Luasan Rencana } \\
(\mathrm{Ha})\end{array}$ & $\begin{array}{c}\text { Luas Lahan Belum } \\
\text { Terbangun } \\
\end{array}$ \\
\hline 1 & Paser & $3.944,22$ & 62.298 & 58.354 \\
\hline 2 & Kutai Barat & $1.359,79$ & 11.311 & 9.951 \\
\hline 3 & Kutai Kartanegara & $9.558,63$ & 63.928 & 54.369 \\
\hline 4 & Kutai Timur & $9.906,89$ & 79.923 & 70.016 \\
\hline 5 & Berau & $5.818,32$ & 76.643 & 70.825 \\
\hline 6 & Penajam Paser Utara & $3.342,2$ & 27.123 & 23.781 \\
\hline 7 & Balikpapan & $8.905,67$ & 25.318 & 16.412 \\
\hline 8 & Samarinda & 12.910 & 39.156 & 26.246 \\
\hline 9 & Bontang & $3.024,09$ & 7.775 & 4.751 \\
\hline 10 & Mahakam Ulu & $1.38,941$ & 2.790 & 2.651 \\
\hline \multicolumn{2}{|c|}{$\begin{array}{l}\text { Total Kawasan Peruntukan } \\
\text { Permukiman }\end{array}$} & $58.908,8$ & 396.266 & 337.356 \\
\hline
\end{tabular}

Sumber : Perda RTRW Provinsi Kalimantan Timur 
Terkait perumahan dan kawasan permukiman yang berada di daerah lintas kabupaten/kota didapatkan beberapa kawasan seperti Perumaan Khusus Perusahan dan Perumahan Nasional (Perumnas) yang berada di kawasan perbatasan yang bukan MBR dan MBR. Agar tidak terjadi perbedaan proses pembinaan pada daerah lintas kabupaten/kota (fasilitasi).

Tabel 6. Luas Lahan Permukiman di kawasan Perbatasan antar kabupaten/kota

\begin{tabular}{ccr} 
No & Permukiman Perbatasan & Luas Lahan Permukiman (Ha) \\
\hline 1 & Balikpapan - Kukar & 336,31 \\
2 & Bontang - Kutim & $1.290,75$ \\
3 & Samarinda - Kukar & $2.420,88$ \\
4 & Penajam - Paser & 157,37 \\
5 & Botang - Kukar & 0,02 \\
\hline Sumber
\end{tabular}

Sumber : Hasil Analisis

Berikut ini dalam tabel 7. merupakan lokasi perumahan dan kawasan permukiman yang berada pada lintas daerah Kabupaten/kota yang ada di Provinsi Kalimantan Timur.

Tabel 7. Lokasi Perbatasan atau lintas Daerah di Provinsi Kalimantan Timur

\begin{tabular}{|c|c|c|}
\hline $\begin{array}{c}\text { BERADA PADA } \\
\text { PERBATASAN ANTAR } \\
\text { KAB. / KOTA }\end{array}$ & PERBATASAN DESA/KELURAHAN & KETERPADUAN \\
\hline PPU-PASER & Desa Rintik-Desa Longkali & Pusat Provinsi, Kabupaten/ Kota \\
\hline BPP-KUKAR & Kel. Karang Joang-Karya Merdeka & Pusat Provinsi, Kabupaten/ Kota \\
\hline KUKAR-SMD & Loa Janan Ulu-Kel. Simpang Tiga & Pusat Provinsi, Kabupaten/ Kota \\
\hline KUKAR-SMD & Sanga sanga-Desa Batuas & Pusat Provinsi, Kabupaten/ Kota \\
\hline KUKAR-SMD & Sungai Meriam-Desa Sindangsari & Pusat Provinsi, Kabupaten/ Kota \\
\hline KUKAR-SMD & Desa Tanah Datar-Kelurahan Sungai Siring & Pusat Provinsi, Kabupaten/ Kota \\
\hline KUKAR-KUTIM & Santan Ulu-Danau Redan & Pusat Provinsi, Kabupaten/ Kota \\
\hline BONTANG-KUTIM & Kel. Telihan-TIk Pandan & Pusat Provinsi, Kabupaten/ Kota \\
\hline KUTIM-BERAU & Miau baru-Simpang Letak & Pusat Provinsi, Kabupaten/ Kota \\
\hline KUKAR-KUBAR & Perian-Bongan & Pusat Provinsi, Kabupaten/ Kota \\
\hline
\end{tabular}

Sumber : Hasil Analisis

Pada kawasan tersebut Pemerintah Provinsi hendaknya dapat membentuk Unit Keterpaduan Perumahan dan Kawasan Permukiman Daerah Lintas Batas yang berfungsi untuk memantau kualitas perumahan dan permukimannya. Berdasarkan hal tersebut maka perlu adanya arahan keterpaduan pemanfaatan dan pengendalian pembangunan perumahan dan kawasan permukiman pada kawasan lintas daerah kabupaten/kota. Keterpaduan pemanfaatan dan pengendalian pembangunan perumahan dan kawasan permukiman pada daerah lintas kabupaten/kota menjadi sangat penting karena merupakan kewenangan pemerintah provinsi dalam hal ini adalah gubernur. Sebagaimana diatur didalam Peraturan Daerah Provinsi Kalimantan Timur No. 1 Tahun 2016 tentang Rencana Tata Ruang Wilayah Provinsi Kalimantan Timur pada pasal 57 mengenai perizinan yang menyatakan Izin pemanfaatan ruang diberikan oleh pejabat yang berwenang sesuai dengan kewenangannya.

Terkait dengan pengelolaan kawasan sesuai dengan rencana tata ruang wilayah provinsi Kalimantan Timur untuk kawasan permukiman dapat dikembangkan sebagai berikut:

1. Pengembangan kawasan budidaya yang secara teknis dapat digunakan untuk permukiman harus aman dari bahaya bencana alam, sehat, mempunyai akses untuk kesempatan berusaha dan dapat memberikan manfaat bagi peningkatan ketersediaan permukiman, 
Arahan Keterpaduan Pemanfaatan dan Pengendalian Pembangunan Perumahan dan Kawasan Permukiman Pada Lintas Daerah Kabupaten/Kota

Mohtana Kharisma Kadri, Faisal

mendayagunakan fasilitas dan utilitas disekitarnya serta meningkatkan sarana dan prasarana perkembangan kegiatan sektor ekonomi yang ada.

2. Pengembangan permukiman perdesaan dilakukan dengan menyediakan fasilitas dan infrastruktur secara berhirarki sesuai dengan fungsinya sebagai: pusat pelayanan antar desa, pusat pelayanan setiap desa, dan pusat pelayanan pada setiap dusun atau kelompok permukiman.

3. Menjaga kelestarian permukiman perdesan khususnya kawasan pertanian.

4. Pengembangan permukiman perkotaan dilakukan dengan tetap menjaga fungsi dan hirarki kawasan perkotaan serta tetap memperhatikan proporsi kawasan terbangun terhadap ruang terbuka baik berupa ruang terbuka hijau dan ruang terbuka non hijau.

5. Membentuk pengelompokan permukiman untuk menghindari penumpukan dan penyatuan antar kawasan permukiman, dan diantara cluster permukiman disediakanruang terbuka hijau.

6. Perkembangan perkotaan menengah dilakukan dengan membentuk pelayanan wilayah yang mampu mendorong pertumbuhan wilayah sekitarnya.

7. Permukiman perkotaan kecil dilakukan melalui pembentukan pusat pelayanan skala kabupaten dan perkotaan kecamatan yang ada di kabupaten.

8. Permukiman kawasan khusus seperti penyediaan tempat peristirahatan pada kawasan pariwisata, kawasan permukiman baru sebagai akibat perkembangan infrastruktur, kegiatan sentra ekonomi, sekitar kawasan industri, dilakukan dengan tetap memegang kaidah lingkungan hidup dan bersesuaian dengan RTRW masing-masing kabupaten/kota.

Agar tidak terjadi perbedaan konsep pengembangan ruang perkotaan dan permukiman pada daerah lintas kabupaten/kota tersebut, rencana tata ruang wilayah perlu disusun mulai dari level nasional dan daerah agar keterpaduan rencana pemanfaatan dan pengendalian yang lebih detail dapat terwujud yakni perumahan dan kawasan permukiman yang berkualitas dan berkelanjutan.

Keterpaduan dalam perencanaan mulai dari dokumen perencanaan ruang yang bertujuan untuk mengintegrasikan pembangunan infrastsruktur wilayah nasional, regional, wilayah dan intra daerah dalam wilayah provinsi. Melalui keterpaduan, maka infrastruktur seperti kebinamargaan, keairan, keciptakaryaan dan perumahan rakyat menjadi terpadu.

Terkait dengan arahan pemanfaatan dan pengendaliannya, perumahan dan kawasan permukiman yang berada pada daerah lintas batas kabupaten kota dapat dibagi dalam dua kelompok yakni permukiman perkotaan dan pedesaan. Permukiman yang berada pada kawasan perkotaan dan perdesaan diarahkan seperti pada tabel 8.

Sedangkan untuk pengawasan dan penertiban pembangunan pada kawasan lintas daerah kabupaten/kota terkait perumahan dan kawasan permukiman, sebagaimana amanat dalam Undang-Undang No. 1 Tahun 2011 tentang Perumahan dan Kawasan Permukiman pada pasal (81) tentang pengendalian dan kawasan permukiman. Dijelaskan bahwa pemerintah dan pemerintah daerah sesuai dengan kewenangannya bertanggung jawab melaksanakan pengendalian dalam penyelenggaraan kawasan permukiman.

Adapun tujuan dari pengendalian tersebut, agar dalam penyelenggaraan perumahan dan kawasan permukiman dimaksudkan untuk:

1. Menjamin pelaksanaan pembangunan permukiman dan pemanfaatan permukiman sesuai dengan rencana kawasan permukiman;

2. Mencegah tumbuh dan berkembangnya perumahan kumuh dan permukiman kumuh; dan

3. Mencegah terjadinya tumbuh dan berkembangnya lingkungan hunian yang tidak terencana dan tidak teratur. 
Tabel 8. Arahan Keterpaduan pemanfaatan dan pengendalian Perumahan dan Kawasan Permukiman pada daerah lintas Kabupaten/kota

\begin{tabular}{|c|c|c|}
\hline Nama & Desa/Kelurahan & Arahan Operasional \\
\hline PPU-PASER & $\begin{array}{l}\text { Desa Rintik-Desa } \\
\text { Longkali } \\
\text { Kel. Karang Joang- } \\
\text { Karya Merdeka }\end{array}$ & $\begin{array}{l}\text { 1. indikasi arahan peraturan zonasi untuk kawasan peruntukan } \\
\text { permukiman perkotaan terdiri dari: } \\
\text { - diijinkan pengembangan rumah tunggal, apartemen, } \\
\text { cluster perumahan; } \\
\text { - intensitas bangunan berkepadatan sedang - tinggi; }\end{array}$ \\
\hline KUKAR-SMD & $\begin{array}{l}\text { Loa Janan Ulu-Kel. } \\
\text { Simpang Tiga }\end{array}$ & $\begin{array}{l}\text { - zona perumahan harus terlayani oleh minimum satu moda } \\
\text { sarana umum angkutan massal pada kawasan } \\
\text { berkepadatan sedang, dan minimum dua moda sarana } \\
\text { umum angkutan massal pada kawasan berkepadatan } \\
\text { tinggi; }\end{array}$ \\
\hline KUKAR-SMD & $\begin{array}{l}\text { Sungai Meriam-Desa } \\
\text { Sindangsari }\end{array}$ & $\begin{array}{l}\text { - boleh mengembangkan perdagangan jasa dengan syarat } \\
\text { sesuai dengan skalanya; } \\
\text { - diijinkan pengembangan fasilitas umum dan fasilitas sosial }\end{array}$ \\
\hline KUKAR-SMD & $\begin{array}{l}\text { Desa Tanah Datar- } \\
\text { Kelurahan Sungai }\end{array}$ & $\begin{array}{l}\text { sesuai skalanya; } \\
\text { dilarang pengembangan budidaya lainnya. }\end{array}$ \\
\hline & Cantan I I Rangu & $\begin{array}{l}\text { 2. indikasi arahan peraturan zonasi untuk kawasan permukiman } \\
\text { perdesaan terdiri dari: }\end{array}$ \\
\hline $\begin{array}{l}\text { KUKAR- } \\
\text { KUTIM }\end{array}$ & $\begin{array}{l}\text { Santan Ulu-Danau } \\
\text { Redan }\end{array}$ & $\begin{array}{l}\text { - diijinkan pengembangan rumah tunggal, cluster } \\
\text { perumahan, rumah susun (flat); }\end{array}$ \\
\hline BONTANG- & Kel. Telihan-TIk & - intensitas bangunan berkepadatan rendah - sedang; \\
\hline KUTIM & Pandan & $\begin{array}{l}\text { - boleh mengembangkan perdagangan jasa dengan syarat } \\
\text { sesuai dengan Skalanya, }\end{array}$ \\
\hline KUTIM- & Miau baru-Simpang & $\begin{array}{l}\text { - Diijinkan pengembangan fasilitas umum dan fasilitas sosial } \\
\text { sesuai dengan skalanya }\end{array}$ \\
\hline BERAU & Letak & - Dilarang pengembangan budidaya lainnya. \\
\hline $\begin{array}{l}\text { KUKAR- } \\
\text { KUBAR }\end{array}$ & Perian-Bongan & \\
\hline
\end{tabular}

Sumber : Hasil Analisis

Selanjutnya dijelaskan bahwa pengawasan yang dilakukan oleh pemerintah dan pemerintah daerah dilakukan mulai tahap perencanaan, pembangunan dan pemanfaatan. Pengendalian kawasan permukiman dilakukan pada lingkungan hunian perkotaan dan lingkungan hunian perdesaan. Pengendalian lingkungan hunian perkotaan dilakukan pada pengembangan perkotaan dan perkotaan baru, sedangkan lingkungan hunian perdesaan dilakukan pada pengembangan perdesaan sebagai pusat pertumbuhan ekonomi, sosial/budaya perdesaan.

Pengendalian pada tahap perencanaan dilakukan dengan mengawasi rencana penyediaan prasarana, sarana dan utilitas umum sesuai dengan standar pelayanan minimal dan memberikan batas zonasi lingkungan hunian dan tempat kegiatan pendukung. Pengendalian ini dilakukan sesuai dengan rencana tata ruang wilayah.

Pada tahap pembangunan, dilakukan pengawasan dan pengendalian dengan tujuan untuk menjaga kualitas pembangunan permukiman, yang dilakukan meliputi kegiatan pemantauan, evaluasi dan pelaporan. Pemantauan yang dilakukan merupakan kegiatan pengamatan langsung terhadap penyelenggaraan kawasan permukiman secara langsung, tidak langsung dan/atau melalui laporan masyarakat. 
Arahan Keterpaduan Pemanfaatan dan Pengendalian Pembangunan Perumahan dan Kawasan Permukiman Pada Lintas Daerah Kabupaten/Kota

Mohtana Kharisma Kadri, Faisal

\section{KESIMPULAN}

Proses aglomerasi suatu kawasan yang diawali dengan adanya proses konurbasi dalam sebuah kawasan pada lintas daerah akan menimbulkan dampak yang kurang baik bagi daerah tersebut, terutama bagi perumahan dan kawasan permukiman yang menjadi salah satu faktor perkembangan suatu wilayah. Oleh sebab itu, perlu adanya perencanaan yang matang dalam pemanfaatan lahan untuk perumahan dan kawasan permukiman. Tidak cukup hanya perencanaan saja yang terintegrasi dan terpadu pada tingkatan pusat, provinsi hingga kabupaten/kota, namun juga diperlukan proses pengendalian dalam sebuah perencanaan suatu wilayah atau kawasan sehingga pertumbuhan perumahan dan kawasan permukiman dapat teratur, berkualitas dan berkelanjutan, terutama pada rumah yang dibangun secara mandiri (perseorangan), yang sering kali telah terbangun terlebih dahulu baru melakukan proses perijinan dan lain sebagainya.

Kemudian dalam proses pengawasan dilakukan pada saat pelaksanaan hingga setelah selesai kegiatan pembangunan perumahan dan kawasan permukiman, agar tidak terjadi perubahan kualitas perumahan dan permukiman. Adapun arahan perumahan dan permukiman yang berada pada lintas daerah sebagai berikut :

1. Arahan peraturan zonasi untuk kawasan peruntukan permukiman perkotaan terdiri dari:

- diijinkan pengembangan rumah tunggal, apartemen, cluster/kelompok perumahan;

- intensitas bangunan berkepadatan sedang - tinggi;

- boleh mengembangkan perdagangan jasa dengan syarat sesuai dengan skalanya;

- diijinkan untuk melakukan pengembangan fasilitas umum dan fasilitas sosial sesuai skalanya;

- dilarang untuk melakukan pengembangan budidaya lainnya.

2. Arahan peraturan zonasi untuk kawasan permukiman perdesaan terdiri dari:

- diijinkan untuk melakukan pengembangan rumah tunggal, pengelompokan perumahan, rumah susun (flat);

- intensitas bangunan berkepadatan rendah - sedang;

- boleh mengembangkan perdagangan jasa dengan syarat sesuai dengan Skalanya,

- Diijinkan pengembangan fasilitas umum dan fasilitas sosial sesuai dengan skalanya

- Dilarang pengembangan budidaya lainnya.

\section{REKOMENDASI}

Substansi pengaturan dalam Rancangan Peraturan Daerah tentang Rencana Pembangunan dan Pengembangan Perumahan dan Kawasan Permukiman Provinsi Kalimantan Timur merupakan acuan operasionalisasi bagi pemerintah daerah, yang perlu ditindaklanjuti ke dalam:

a. Peraturan Bupati/Walikota tentang Rencana Pembangunan dan Pengembangan Perumahan Dan Kawasan Permukiman Kabupaten/Kota; serta

b. Keputusan Bupati/Walikota tentang Penetapan Kawasan yang dilarang untuk Lokasi Pembangunan dan Pengembangan Perumahan dan Kawasan Permukiman pada Kabupaten/Kota, seperti pada kawasan bencana, kawasan konservasi dan lain sebagainya.

\section{UCAPAN TERIMAKASIH}

Kami mengucapkan terima kasih kepada semua pihak yang telah membantu dalam proses penelitian ini, baik instansi terkait seperti Dinas PU PERA Provinsi Kalimantan Timur, Tim penyusun laporan penelitian, dan yang lainnya yang tidak dapat kami sebutkan satu persatu. Tidak lupa kami juga ucapkan terimakasih kepada penelaah dan mereview hasil penelitian ini, khususnya para Mitra Bestari Jurnal Riset Pembangunan. 


\section{DAFTAR PUSTAKA}

Anggoro, Bagus. (2019) Pindah ibu kota, "pemburu" tanah sambangi Sungai Merdeka hingga Semoi. dari https://www.antaranews.com/berita/1033982/pindah-ibu-kota-pemburutanah-sambangi-sungai-merdeka-hingga-semoi. Diakses pada pada tanggal 28 Agustus 2019.

Badan Pusat Statistik Kalimantan Timur. (2019). Statistik Indonesia Tahun 2019. Kalimantan Timur : Badan Pusat Statistik.

Ciptakarya (2019). Panduan Identifikasi Kawasan Kumuh. Dari http://ciptakarya.pu.go.id/dok/hukum/pedoman/panduan_identifikasi_kawasan_permuki man_kumuh.pdf. Diakses pada 30 Januari 2020.

Ekartaji, Prittaningtyas dkk. (2014). Kajian Kualitas Lingkungan Permukiman di Daerah Pinggiran Kota Kasus di Desa Ngestiharjo, Yogyakarta. Majalah Geografi Indonesia Vol. 28, No. 1. Universitas Gadjah Mada: Yogyakarta.

E-rtlh. (2019) Data Backlog .Dari http://datartlh.perumahan.pu.go.id. Diakses pada 30 Januari 2020

Nursid Sumaatmadja. (1988). Studi Geografi Suatu Pendekatan dan Analisa Keruangan. Alumni:Bandung.

Peraturan Daerah Provinsi Kalimantan Timur Nomor 1 Tahun 2016 tentang Rencana Tata Ruang Wilayah Provinsi Kalimantan Timur Tahun 2016-2036.

Peraturan Pemerintah Republik Indonesia nomor 14 tahun 2016 tentang Penyelenggaraan Perumahan dan Permukiman.

Permen PU No 217/KPTS/M/2002 tentang Kebijakan dan Strategi Nasional Perumahan dan Permukiman.

Sadyohutomo. (2008). Manajemen Kota dan Wilayah. Bumi Aksara: Jakarta.

Undang-Undang Nomor 1 Tahun 2011 tentang Perumahan dan Permukiman. 